\title{
Monoclonal gammopathy associated with visceral leishmaniasis
}

\begin{abstract}
Monoclonal gammopathy can accompany diverse conditions and is usually benign. It should be distinguished from monoclonal gammopathy of undetermined significance (MGUS) which can rarely turn malignant. Visceral leishmaniasis has only rarely been associated with monoclonal gammopathy. We describe the case of a 55-year-old male who had monoclonal gammopathy associated with visceral leishmanisais, which reversed with stibogluconate therapy.
\end{abstract}

Keywords: visceral leishmaniasis, monoclonal gammopathy.

[Braz J Infect Dis 2010;14(3):297-298]@Elsevier Editora Ltda.

\section{INTRODUCTION}

Monoclonal gammopathy can accompany a number of diverse conditions including infections, haematological malignancies and dermatological conditions. Occasionally, it can be detected incidentally without any underlying predisposition and is then termed monoclonal gammopathy of undetermined significance (MGUS). Only rarely has visceral leishmaniasis been implicated as a cause. We present the case of a 55-year-old male who had a monoclonal gammopathy associated with visceral leishmaniasis, which reversed with therapy.

\section{CASE HISTORY}

A 55-year-old male presented with history of fever of two months duration. He had high fever associated with chills and rigors. There was no associated cough, expectoration, abdominal pain, loose stools, or dysuria. The patient had been anorexic and had lost six kilograms of weight over the past two months. He was originally a resident of Bihar (an area endemic for visceral leishmaniasis). He had no history of treatment for visceral leishmaniasis or tuberculosis.

At the time of presentation, he was febrile $\left(39.4^{\circ} \mathrm{C}\right)$ and appeared pale. Abdominal palpation revealed mild hepatomegaly (liver span-16 $\mathrm{cm}$ ) and a moderately enlarged firm spleen. His $\mathrm{CBC}$ revealed a normocytic normochromic anemia (Hb-6.9 g/dL, MCV-93.8 fL, and MCH-
$29.6 \mathrm{pg})$, decreased leukocytes $\left(1,900 / \mathrm{cel} \mathrm{mm}^{3}\right)$, and thrombocytopenia $\left(74,000 / \mathrm{cel} \mathrm{mm}^{3}\right)$. Serum proteins were elevated with increased globulin levels (total protein-9.1 g/dL, albumin-3.0 g/dL, globulin-6.1 g/dL and A: G ratio of 1:2). Under clinical suspicion of visceral leishmaniasis, a bone marrow aspiration (BMA) was performed. BMA revealed LD bodies and showed a significant increase in number of mature plasma cells to $16 \%$. In view of raised globulins and evidence of plasmacytosis, a serum protein electrophoresis was done. This revealed presence of $\mathrm{M}$-spike over an underlying polyclonal hypergammaglobulinemia (total protein-8.7 g/dL, albumin-3.13 g/dL, alpha1 globulin-0.43 g/dL, alpha2-0.44 g/dL, beta2-0.57 g/dL, gamma- $4.13 \mathrm{~g} / \mathrm{dL}$ ). The serum calcium was $7.9 \mathrm{mg} / \mathrm{dL}$ and the skeletal survey was normal. Patient could not afford the further testing to characterize the M band. The serology for $\mathrm{k} 39$ antibody was positive and the patient was treated with sodium stibogluconate for a month. In the course of his stay, the hepatosplenomegaly regressed, his serum globulins had fallen (total proteins-7.2 $\mathrm{g} / \mathrm{dL}$, albumin- $3.7 \mathrm{~g} / \mathrm{dL}$, globulin-3.5 g/dL). His hematological parameters

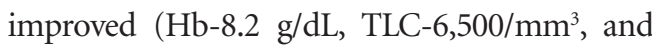

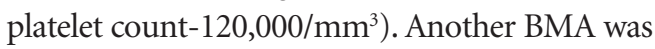
done on completion of 28 days therapy and sodium stibogluconate revealed only $4 \%$ plasma cells with no LD bodies. At three months of follow-up, no M spike was detected and the patient was asymptomatic with normal globulins (serum globulin-2.3 g/dL).
Authors

Vishal Sharma, MD $^{1}$

Mukul P Agarwal, MD $^{1}$

Subhash Giri, MD ${ }^{1}$

${ }^{1}$ Department of Medicine, University College of Medical Sciences, Delhi, India.

Submitted on: 03/08/2010 Approved on: 03/15/2010

Correspondence to:

Dr Vishal Sharma, MD University College of

Medical Sciences, Delhi, India.

19 Gobind nagar Subhash Road Chheharta Amritsar India

Phone: +91-9873093740 E-mail: docvishalsharma@ gmail.com

We declare no conflict of interest. 


\section{DISCUSSION}

Monoclonal gammopathies are disorders associated with formation of M spike (band of monoclonal protein usually in the $\gamma$ globulin region. Usually, this results from plasma cell disorders but might accompany a variety of diseases including solid tumors (colon, breast), sarcoidosis, parasitic diseases, rheumatoid arthritis, AIDS, chronic liver disease (especially HCV related), lichen myxedematosus, pyoderma gangrenosum, etc. ${ }^{1}$

Polyclonal hypergammaglobulinemia is a common feature of visceral leishmaniasis. Only a few case reports in the past have implicated visceral leishmaniasis as an etiology of monoclonal gammopathy. ${ }^{2-4}$ In one case, the patient had a monoclonal triple band. ${ }^{2}$ In few cases BMA did not reveal LD bodies, and antileishmanial serology was utilized to establish the diagnosis. In two of the published cases, as well as in our case, BMA revealed plasmacytosis that disappeared with therapy. ${ }^{2,3}$ Visceral leishmaniasis has also been implicated as a cause of cryoglobulinemia. ${ }^{5}$ These manifestations of visceral leishmaniasis have been proposed to be a result of chronic antigenic stimulation that occurs in these patients. ${ }^{4}$

Monoclonal gammopathy associated with visceral leishmaniasis should be distinguished from monoclonal gammopathy of undetermined significance (MGUS). MGUS is usually detected incidentally but is known to progress to malignancy with time. ${ }^{1}$ Also, the monoclonal protein in MGUS does not disappear with time, and yearly screening should be done to rule out transformation into malignant monoclonal gammopathy. In contrast, $M$ spike in visceral leishmaniasis disappears with therapy. Moreover, the recognition of this correlation is important in endemic areas because patients detected as having $\mathrm{M}$ component might be harbouring leishmaniasis. The reported case of visceral leishmaniasis is rare one, but is a potentially treatable cause of monoclonal gammopathy; therefore, it should be considered in the differential diagnosis of monoclonal gammopathy, especially in endemic areas.

\section{REFERENCES}

1. Bladé J. Clinical practice. Monoclonal gammopathy of undetermined significance. N Engl J Med 2006; 355:2765-70.

2. García Menéndez L, Santamaría López C, Fernández Eroles AL, Megido Lahera M, Galende del Canto J, Aguilera Sanz C. Monoclonal component in visceral leishmaniasis: a rare association that can lead to misdiagnosis. Rev Clin Esp 1998; 198:517-20

3. Randi ML, Ruzzon E, Tezza F, Tezza F, Pacquola E, Fabris F. Monoclonal gammopathy in human leishmaniasis. Neth J Med 2006; 64:50-1.

4. Rombola F, Spinoso A, Bertuccio SN. Monoclonal gammopathy after visceral leishmaniasis: just a coincidence? Infez Med $2008 ; 16: 173-4$

5. Casato M, de Rosa FG, Pucillo LP et al. Mixed cryoglobulinemia secondary to visceral Leishmaniasis. Arthritis Rheum 1999; 42:2007-11. 